\title{
A Short History of Managing Problematic Users of Alcohol in Western Australia by Mental Health Services
}

\author{
Greg Swensen (1) \\ Law School, University of Western Australia, Crawley, Australia
}

\begin{abstract}
Aims: This paper examines the role that mental health services (MHS) performed in the management and provision of medical care and treatment of problematic users of alcohol in Western Australia (WA) over the period since 1900. Methods: The research involved an examination of legislative enactments and regulations, records of parliamentary debates in Hansard, administrative records in the State Records Office, and other sources of public information, such as departmental annual reports, reviews of services, studies and newspapers. Results: This research identified three eras of policy involving problematic users. The first, from 1900 to the mid 1970s, focussed on controls in inebriates and lunacy legislation to create a regime of civil commitment, designed to confine and compel 'inebriates', as well as 'convicted inebriates;' to 'dry out' and rehabilitate. The second, between 1975 and the late 1990s, involved the creation of a state-wide system of specialist service providers to provide treatment and recovery for problematic users. The system involved a spectrum of services that included a detoxification hospital, outpatient clinics and community-based regional services established and operated by a statutory public health agency, the Alcohol and Drug Authority (ADA). The third era, which commenced in the late 1990s, involved the transfer of all community-based services from the ADA to 'not-for-profit' non-government organisations (NGOs). The end result of this devolution was the ADA retained only a limited treatment role, as the operator of the inpatient detoxification facility. The balance of its functions were redefined in relation to the prevention of the use of alcohol and other drugs, primarily through support of mass public education programs, as well as oversight of funded NGO programs. The paper concludes with a consideration of a recent major development which involved administrative and legislative actions in 2015 to abolish the statutory body which had operated since 1975 and transfer administrative responsibility for drug and alcohol services into the Mental Health Commission.
\end{abstract}

Keywords: Alcohol, mental health, treatment, Western Australia, inebriates, civil commitment

Eine kurze Geschichte der Rolle der psychiatrischen Gesundheitsdienste in Westaustralien im Umgang mit problematischen Alkoholkonsumenten

Zusammenfassung: Ziele: Dieser Beitrag untersucht die Rolle, die psychiatrische Gesundheitsdienste (MHS) seit 1900 in Westaustralien (WA) bei Bereitstellung und Management der medizinischen Versorgung und Behandlung von problematischen Alkoholkonsumenten gespielt haben. Methode: Untersucht wurden Gesetzesnormen und Verordnungen, Aufzeichnungen von Parlamentsdebatten in Hansard (Titel der offiziellen protokollarischen Aufzeichnungen der Sitzungen des Australischen Parlaments), Verwaltungsaufzeichnungen im State Records Office und anderen öffentlichen Informationsquellen, wie z. B. Jahresberichte der Abteilungen, Übersichten über Dienste, Studien und Zeitungen. Ergebnisse: Die Politik im Bereich “Umgang mit problematischem Alkoholkonsumenten” lässt sich in drei Phasen einteilen. In Phase 1, von 1900 bis Mitte der 1970er Jahre, stand die Kontrolle von Trinkern im Mittelpunkt sowie eine nahezu aberwitzige Gesetzgebung, die darauf abzielte, eine gesellschaftliche Übereinkunft zu schaffen, dass Trinker und "verurteilte Trinker" eingesperrt, unter Zwang "trocken" werden und rehabilitiert werden mussten. In der zweiten Phase, zwischen 1975 und den späten 1990er Jahren, wurde ein landesweites System spezialisierter Behandlungsangebote für problematische Konsumenten geschaffen. Das System bot ein Spektrum von Dienstleistungen, das von Entgiftungskliniken, über Ambulanzen bis zu gemeindebasierten regionalen Diensten reichte, die von der staatlichen Alkohol- und Drogenbehörde (ADA), aufgebaut und betrieben wurden. In der dritten Phase, die Ende der 1990er-Jahre begann, wurden alle gemeindebasierten Dienste von der ADA an gemeinnützige Nichtregierungsorganisationen (NGOs) übertragen. Das Resultat dieser Dezentralisierung war, dass die ADA als Betreiberin der stationären Entgiftungseinrichtungen nur noch eine begrenzte Rolle in der Behandlung spielte. Hier wurde ein Gleichgewicht wiederhergestellt durch eine Neudefinition ihrer Funktion im Bereich der Prävention des Konsums von Alkohol und anderen Drogen, wo sie vor allem öffentliche Massenaufklärungsprogramme unterstützte und die Aufsicht über die finanzierten NGO-Programme hatte. Der Beitrag endet mit einem Blick auf eine wichtige gesundheitspolitische Entwicklung der letzten Zeit. So wurden im Jahr 2015 durch die Regierung administrative und legislative Voraussetzungen geschaffen, um die seit 1975 bestehende Körperschaft des öffentlichen Rechts abzuschaffen und die administrative Verantwortung für die Alkohol- und Drogeneinrichtungen der Mental Health Commission zu übertragen.

Schlüsselwörter: Alkohol, psychische Gesundheit, Behandlung, Westaustralien, Trinker, Ziviles Engagement 


\section{Introduction}

This paper is concerned with the period from 1900 to the present and results from an exploratory study of the policies in WA over this period, which targetted problematic users of alcohol. The research utilises an approach that divided the time frame since 1900 into periods. It is suggested this is a sound means to identify and distinguish policies that operated at different times over the period in WA, as 'periodization in history ... is not a fact, but a necessary hypothesis or tool of thought' (Carr, 1961, p. 60).

This approach relies on the analysis of a range of historical information, undertake a more a Foucauldian-like discourse to develop a broader understanding of how concepts that underpinned these policies evolved and how effectively they dealt with the problem.

To inform further research, at this stage, it is possible to identify a number of competing discourses about problematic use of alcohol. One of these sees the locus of the problem as stemming from individual weakness and moral shortcomings, evidenced by terms like dipsomaniac, inebriate, alcoholic, alcohol dependence and binge drinker. This discourse supports policies to treat and if necessary, compel such individuals to rehabilitate, as they pose risks, even danger, to social order and themselves (Burchell, Gordon, \& Miller, 1991; Kritzman, 1988).

This can be contrasted with a different discourse which emphasises population-wide social controls, such as, the adoption of less or more 'liberal' liquor licensing laws, the characterisation of the use of alcohol as having high social value, and toleration of restrictions on advertising or adoption of 'self-regulation' (McGregor, 2012; Measham, 2004; Measham \& Brain, 2005; Petersen \& Lupton, 1996; Swensen, 2016).

This case study will show that the framework of legislative powers in WA concerned with problematic users of alcohol, can, when studied in detail, provide knowledge about how this problem was managed in a specific jurisdiction. There are some unique characteristics of the State of WA which readers from other jurisdictions may be unfamiliar, relevant to undertaking research of how alcohol policies operate in a small and isolated state within a larger federation.

These characteristics include that WA occupies onethird of the total land area of Australia, with an area of 2.5 million square kilometres (976,000 square miles), yet as it contains about $10 \%$ of the Australian population. As the state has extensive arid areas and a relatively hot climate and employment has involved workforces with much high ratios of males compared to women. This demographic characteristic has been identified as sustaining a culture of heavy drinking, historically symbolised by the importance of hotels in small towns. (Dingle, 1980; Kirkby, 2003, 2006; Kirkby, Luckins, \& McConville, 2010; Pearl, 1969; Phillips, 1980; Sargent, 1979; Stannage, 1981)

However, as the majority of the population is concentrated in the capital of Perth, this means very low population densities outside the capital, where the bulk of the State's economic activity related to mining, processing and agriculture has occurred, since colonial times (Department of Treasury and Finance, 2004).

\section{Methodology}

The research uses information extracted from annual reports of departments and statutory bodies, legislative texts, historical materials, official correspondence and records at the State Records Office, Hansard (record of parliamentary debates), published research and surveys, monographs and newspaper archives.

This information will be used to construct a legislative framework and identify distinguishing features of policies and reforms that over the period. This policy framework will be supplemented by detailed statistical data about the impact of alcohol-related health problems as measured by demands placed on services operated by the MHS over the period.

\section{Results}

\section{Summary}

The case study identified three broad eras of policies and approaches to manage problematic users of alcohol in WA over the period.

The first era, the most enduring, lasted some 75 years, when the MHS managed 'inebriates' through a formal system of committal to a mental health institution for medically managed detoxification.

A second variant of committal was adopted in the mid 1960s, which used a designated prison in addition to the existing role of the MHS. Both approaches had a similar intent, that when an 'inebriate' had 'dried out' they were

\footnotetext{
1 The term 'mental health services' is used in this paper as an overarching term of convenience to describe treatment of problematic users of alcohol in institutional settings, referred to variously as 'asylums', 'reception homes' and 'mental hospitals.'
} 
either discharged or confined under a supervision order for an additional period of time.

The feature of the second era, from the mid 1970s to the late 1990s, was voluntary admission to communitybased treatment programs which supported a spectrum of treatment outcomes, not just abstinence. These programs were established and operated by the ADA, which also provided detoxification of alcohol dependent individuals in a specific purpose hospital, as well as medically supervised treatment to those with dependencies on other drugs. $^{2}$

The third era, operated from the late 1990s until 2015 has involved a circumscribed role for the ADA, limited to operating an inpatient medical detoxification unit, with all remaining treatment services provided as contracted services by NGOs who operate both short and long-term residential facilities and outpatient programs.

\section{First era}

The first era operated from 1900 to the mid 1970s and involved two variants of compelled management, a medically overseen short-stay detoxification in MHS operated 'asylums' and 'mental hospitals'. This approach was expanded in 1963 when a long-stay prison-based system of 'drying out' and a farm work-focussed program based on Alcoholics Anonymous 12-step program was established.

\section{MHS-based medically managed inpatient detoxification}

The basis for dealing with people with mental disorders was the Lunacy Act 1903, which included an option in Part IV to manage 'habitual drunkards'. ${ }^{3}$

The concept of a habitual drunkard in Section 26(2) involved both biological and social considerations, that -

a. the person was suffering from delirium tremens or other dangerous physical effects of habitual drunkenness, or

b. had been wasting his means and been neglecting his business or insufficiently providing for his family, or

c. a wife has been wasting the means of her husband, or

d. such person has recently, under the influence of drink, used or threatened violence towards himself or any member of his family.
A difficulty in the Lunacy Act 1903 was Section 27, which permitted committal for up to 12 months, if supported by evidence from not less than two medical practitioners, for such a person to be held in 'a ward, division, or compartment thereof in which lunatics are not detained for curative treatment'.

The MHS sought to create a perceived separation of habitual drunkards from 'lunatics' by gazetting areas within existing facilities. Initially, from 1914 up until 1918, male inebriates were sent to the Inebriate Section at a farmbased facility, Whitby Falls Asylum, south of the Perth metropolitan area.

However, from comments in annual reports of the Inspector General of the Insane indicate this was an unsatisfactory arrangement from the MHS perspective, as noted in the 1917/1918 annual report.

'Those at Whitby, who were committed Under Sections 7 and 8 of the Act, usually adopt an attitude of passive resistance, refuse treatment, and, generally speaking, are subordinate, and I have throughout found myself in an awkward position, as neither the Act nor Regulations vest me with the power to enforce the necessary discipline.' (Inspector General of the Insane, 1918, p. 5)

Female inebriates were sent to Greenplace, a metropolitan facility for women with mental disorders, which opened in 1916. However, the arrangement at Greenplace was also problematic for the MHS, even though received some inebriates over the next few years.

In July 1918 an option for managing inebriates was created under a provision in the Lunacy Act 1903 by gazetting 'inebriate homes' operated by the Salvation Army, a men's facility in Claremont and a women's facility in Lincoln Street in Highgate. The default arrangement was committal to the Claremont Asylum. ${ }^{4}$

However, in spite of early enthusiasm, usage of these two inebriate homes declined and ceased to operate by the late 1920s.

'The number of Inebriates which has been dealt with by the Salvation Army authorities at the Male Inebriate Home has been very small and the Salvation Army authorities are contemplating close the Home as they are losing a considerable sum of money in its upkeep.

2 Note: The Convicted Inebriates Rehabilitation Act 1963 (CIRA) was amended in 1974, as part of the Alcohol and Drug Authority reforms, which transferred functions in the CIRA to the ADA. However, none of these were activated by the Director of the ADA and CIRA was repealed in 1989 by the Convicted Inebriates' Rehabilitation Repeal Act 1989.

3 This may have adopted the meaning of 'habitual drunkard' in the Section of the 65(6) of the Police Act 1982.

4 The Claremont Hospital for the Mentally Insane was renamed the Claremont Mental Hospital in 1933 and in 1967 after the word 'Mental' was removed from its title it became known as the Claremont Hospital. 
When this home is closed there will be no institution to deal with the type of inebriate which has been admitted there, and it is for the Government to decide what steps, if any, it should take to provide accommodation for this class. The non-convicted type of inebriate is provided for by a portion of a ward being set apart for their accommodation at the Claremont Hospital for the Insane.' (Inspector General of the Insane, 1928, p. 2)

As observed by the Inspector General of the Insane in his 1925-1926 annual report, inebriate homes were a fraught proposition as they involved a divergence between the objectives of the MHS and the prison system.

'The Inebriates Homes were provided for the treatment of inebriates and the object has largely been defeated by the short periods ordered, and it is obviously impossible to treat an inebriate for a short period of time, say three weeks. It is very evident that a period of three weeks by any stretch of imagination cannot be considered as treatment, but is intended as a punishment.'

The proper place for any person so committed is surely the Fremantle Prison. Under such circumstances the votes of my department are bearing a charge which in no way belongs to them and which I am powerless to obviate.' (Inspector General of the Insane, 1926, p. 7)

The Lunacy Act 1903 also provided another option, to admit inebriates to a 'reception home' for no more than six months, as a 'voluntary boarder'. However, there seemed to be limited support for this option, because it was considered that 'a person had to have enough insight into his own behaviour and feelings to know that he was ill and needed treatment, and the ability to decide for himself to seek admission' (Ellis, 1984, p. 84).

There was intense pressure in the first decade of the twentieth century to manage the high rates of social disorder associated with alcohol, by relying on rigorous enforcement of provisions in the Police Act $1892 .{ }^{5}$ A response to this involved use of powers to control and confine problematic users of alcohol with the Inebriates Act 1912. This provided a broad definition of an 'inebriate', being 'a person who habitually uses intoxicating liquor or intoxicating narcotic drugs to excess.' (Section 2), to resolve the shortcomings of criminal law response and the concept of a habitual drunkard (Straw, 2013).
This legislation had a potentially wide coverage as it enabled the courts through civil commitment to manage a spectrum of individuals, beyond those who may have been alcohol dependent, to those where intoxication was a factor in an offence:

Where a person is convicted summarily or on indictment of an offence, and drunkenness is an element, or was a contributing cause of such offence, and on inquiry it appears that the offender is an inebriate, the Court may, in its discretion, order the offender to be placed, for a period of not exceeding twelve months, in an institution established for the reception of convicted inebriates. Section 7(1)

Although there is little evidence of how frequently Section 7(1) was utilised to manage problematic users of alcohol, it was replicated in the Convicted Inebriates Rehabilitation Act 1963. The Inebriates Act 1912 in other respects contained similar provisions as in the Lunacy Act 1903, setting out three pathways for committal of an inebriate-

a. on the application by the person themselves, or

b. by the spouse, siblings or adult children or a business partner, or

c. by a medical practitioner.

The legislation also provided on release an inebriate could have conditions attached for up to a further 12 months, requiring him or her to be 'of good behaviour, and abstain from taking or using any intoxicating liquor or intoxicating or narcotic drug'. Section 12(2).

In the late 1920s another option was adopted to admit problematic users of alcohol as voluntary patients to Heathcote Reception Home, which opened in February 1929. This was subsequently renamed Heathcote Hospital and operated under the Mental Treatment Act 1927, not under the Lunacy Act 1903. However, it is likely voluntary admissions to Heathcote Hospital could have depended on whether an individual met the 'insight' test quoted earlier.

An impetus the 1927 legislative reform arose from a scathing review by a Royal Commission in 1922 that identified profound shortcomings of the asylum-centric system that had operated under the Lunacy Act 1903.

'There is no marked line dividing sanity from insanity; there are degrees intervening which must be recognised and provided for. Beyond the observation wards at the Perth and Kalgoorlie Hospitals (which

\footnotetext{
5 In WA until the early 1920 about one third of all charges for all offences dealt with by the police were for public drunkenness, which meant that many finished up in the prison system, as they were repeat offenders: (Swensen, 2017)
} 
are insufficient for the purpose), there is no institution in Western Australia which can deal effectively with this important question; there is, so to speak, nothing between sanity and Claremont.

The Perth and Kalgoorlie observation wards more or less fulfil the function performed by the Darlinghurst Reception House in Sydney, which deals very largely with acute alcoholic cases and a comparatively small proportion of cases of early mental disorder.' (Royal Commission In Lunacy, 1922, p. 7)

Although Heathcote Hospital may have provided treatment over the period up to the early 1960s, the major role in WA of managing those acutely or chronically affected by use of alcohol through 'drying out' was performed by the Claremont Asylum.

This key role undertaken by Claremont Asylum started to change from the mid 1960s, when the Mental Health 1962, which also repealed the Inebriates Act 1912, came into operation on 1 July 1966 . The 1966 reform reflected the commencement of a major shift in the delivery of mental health services driven by the shift in treatment philosophy, away from an institutional to a community-based model of care (Rosen, 2006).

However, whilst involvement of the MHS may have retreated from its long-standing reliance on an institutionalcentric model, the coercive and institutional management of problematic users of alcohol continued under the Convicted Inebriates Rehabilitation Act 1963 (CIRA), which commenced in July $1963 .{ }^{\circ}$

The extent of the role of the MHS in managing problematic users of alcohol is identified in trends of annual numbers of inpatient admissions to mental hospitals in Figures 1 and 2. This data is from annual reports, contained in detailed appendix tables which had breakdowns of admissions by gender and various mental disorders and enabling legislation.

Some caution should be exercised in interpretation of data, as in earlier reports the MHS adopted a 'causes of insanity' classification from $1904 / 1905$ to $1928 / 1929$ and a 'form of mental disorder' classification from 1929/1930 until the International Classification of Diseases and Causes of Death (ICD) classification system was adopted in the 1967/1968 (Mental Health Services, 1996).

The ICD 8 classification was adopted through the Hospital Morbidity Data System (HMDS), which was implemented in January 1971 and managed by the Health Department of WA from January 1981, classified inpatient admissions by health conditions based on coding for a principal condition and addition sub-codes for underlying causes and other conditions that were present (Statistics Branch, 1971, p. 3; Swensen \& Unwin, 1995).

The ICD 8 was supplanted by the ICD 9CM classification used in annual reports from 1970/1971 to 1977/1978 and since 1978/1979, the ICD 10 system was used (Moriyama, Loy, Robb-Smith, Rosenberg, \& Hoyert, 2011).

The annual counts of alcohol-caused mental disorders from 1967/1968 reflect changes stemming from the ICD 8 system, which counted alcohol-related admissions in all public and private hospitals according to the ICD protocols, compared to counts of admissions to MHS hospitals before 1967/1968. It should be noted as these counts refer to only inpatient admissions, they do not count alcoholrelated attendances to MHS-operated outpatient clinics.

Figure 1 has annual counts of alcohol-related admissions to MHS-operated hospitals broken down by gender and shows a predominance of male admissions throughout the period 1904/1905 to 1977/1978.

Figure 2 shows in the first part of the period alcohol-related admissions were a substantial proportion of all types of admissions to the MHS hospitals, representing up to about one in three of all admissions in the first decade of the twentieth century.

Over the remainder of the period, about $15 \%$ of annual admissions were alcohol-related mental disorders. The decline in alcohol-related MHS admissions from 1974/1975 stems from the opening of the ADA, which assumed responsibility for managing problematic users of alcohol, as described below.

\section{Prison-based managed detoxification and rehabilitation}

The second approach, which co-existed alongside the MHS system of detoxification, operated between 1963 and 1975, involved sentencing a 'convicted inebriate', under the CIRA to Karnet Prison, a low security male only farmbased prison. This system was overseen by the Convicted Inebriates Board.

The CIRA legislation meant an adult male who had been convicted of a summary offence, if found at trial to have committed an offence where drunkenness was considered to be either a contributory cause or element of the offence, could be sentenced to 'dry out' and serve a specified period of time, instead of sentenced for the predicate offence.

Even though convicted inebriates were housed in a designated facility within Karnet Prison, it is difficult to style

6 Those admitted to the Inebriates Section at Karnet Prison under the CIRA legislation were referred to as 'trainees', not as prisoners (Inebriates Advisory Board, August 1969, p. 5) 


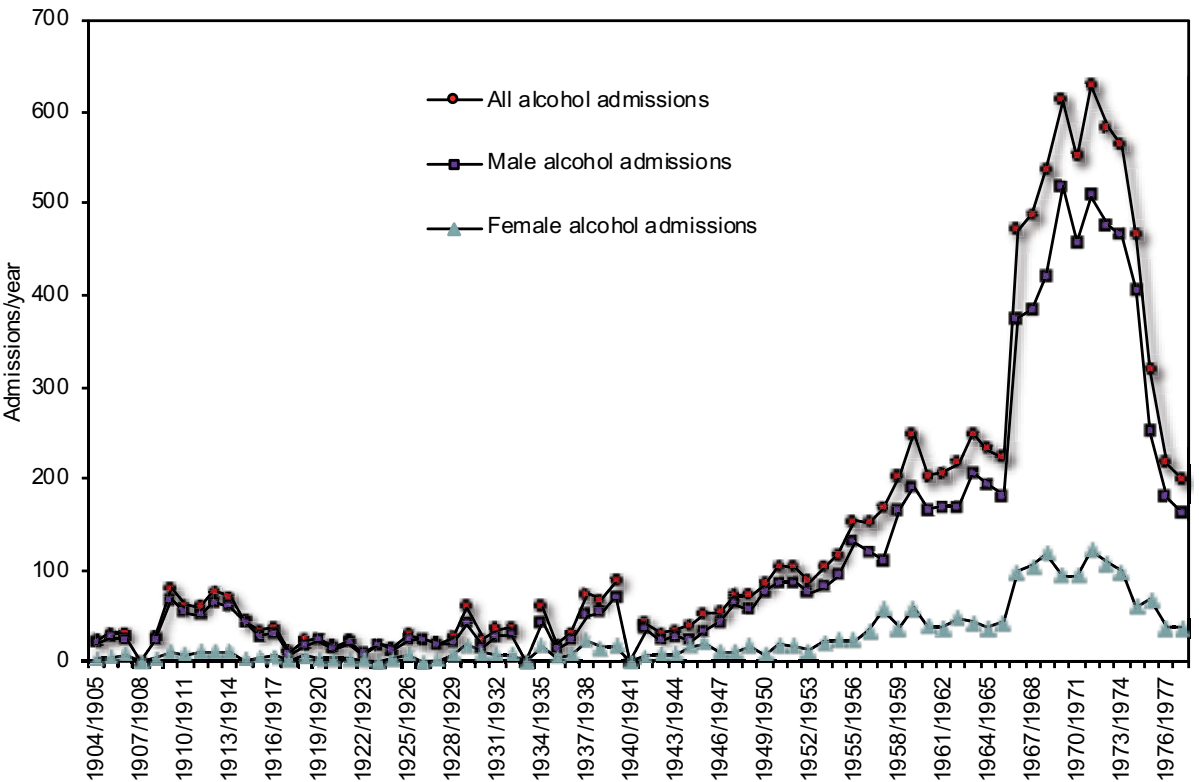

Figure 1. Number of inpatient admissions for alcohol-caused mental disorders by gender, WA, 1904/1905-1977/1978.

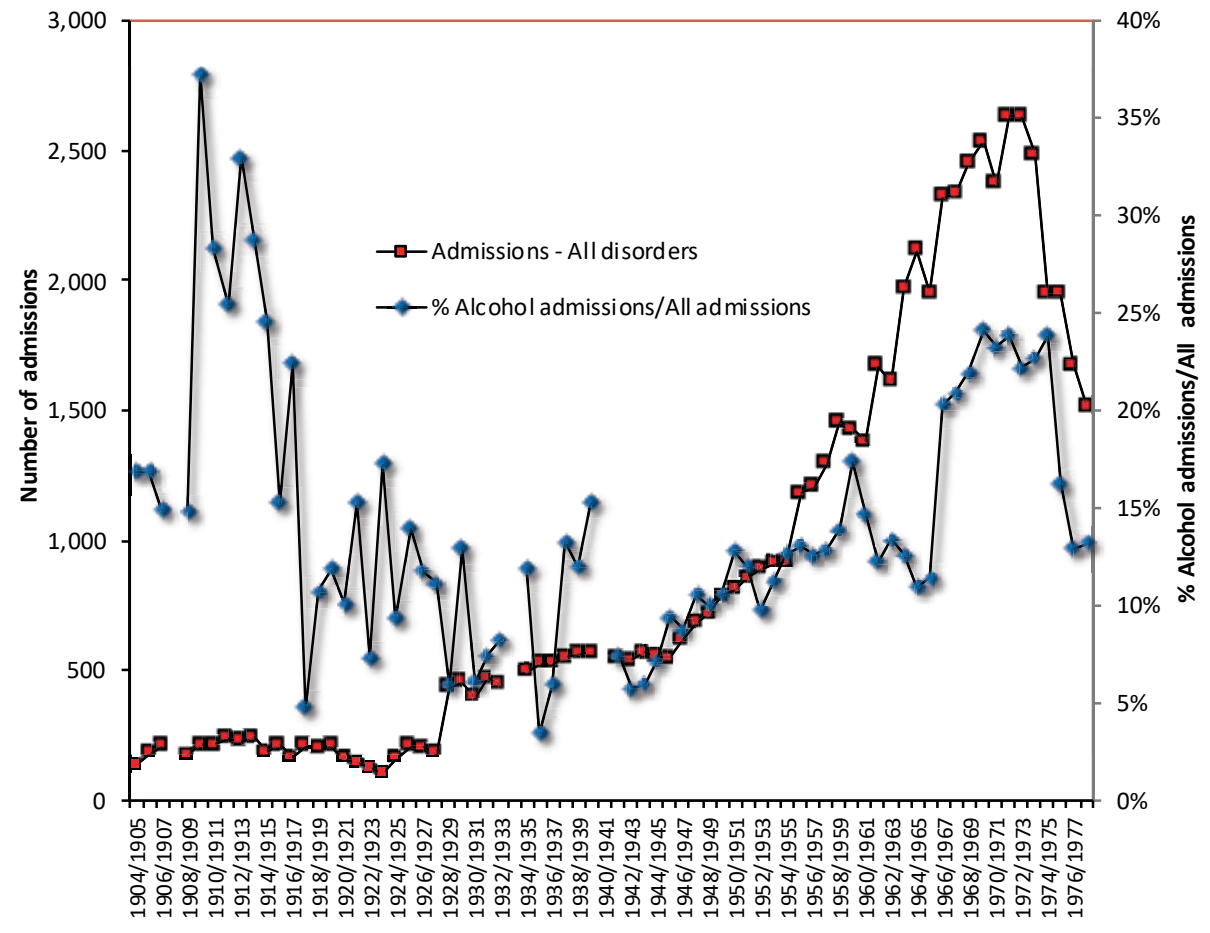

Figure 2. Number of inpatient admissions for all mental disorders, alcohol-caused mental disorders \& $\%$ of alcohol mental disorders of all mental disorders, WA, 1904/1905-1977/1978. this as treatment. Convicted inebriates were regarded as prisoners, as they were subject to the prison's disciplinary framework.

The only account of the operation of this system is a laudatory review of the first six years operation, published in 1969 by the Inebriates Advisory Board. This review asserted out of the 353 men sentenced, 69 (19.5\%) had been sober for 12 months or more, a result of 'inestimable value', as 'we are dealing with the rather hard core of alcoholics'.
'(I)t has to be realised that these people were virtually on the scrap heap and that all these recoveries are in men who in general had previously been given periods of hospitalisation and treatment elsewhere for their alcoholism over the years, but that to date had shown no lasting response. To these men Karnet has been able to give sobriety, a new way of life and an enjoyment of work and society which they had never had before' (Inebriates Advisory Board, August 1969, p. 15). 
In this era a limited role was performed by the Mental Ward at the State's major public hospital involving problematic users of alcohol. This inner-city area hospital, which was established in 1855 , was initially known as the Colonial Hospital, renamed the Perth Public Hospital and since 1946 has been known as Royal Perth Hospital (RPH).

The Mental Ward at RPH operated as an inpatient short term stay and assessment facility for the reception of people with a variety of acute mental disorders. These included specific alcohol-related mental disorders such as alcohol dependence, delirium tremens (DTs), alcoholic psychosis and Korsakov's psychosis.

Some of these patients may have presented at the hospital for alcohol-related medical reasons, such as alcoholic cirrhosis, alcoholic cardiomyopathy, pancreatitis, alcoholic gastritis, or been admitted for other medical conditions.

\section{Second era}

This involves the mid 1970s to the late 1990s, when management of problematic users of alcohol were assumed by the ADA instead of by the MHS. However, although the ADA commenced operating clinical services in November 1974, it was not until Aston Hospital, a specific purpose 29 bed detoxification hospital, was opened in February 1977, was there a specific-purpose hospital to treat acutely intoxicated persons in WA.

'The basic philosophy behind the establishment of a detoxification unit such as Aston Hospital, is to provide a specific centre for the reception of the alcohol or drug intoxicated patient who needs specialized care and treatment immediately on admission.

Many of the alcoholic patients are recidivists and one of the basic aims of Aston Hospital is to counter the "revolving door syndrome" associated with these illnesses.' (Western Australian Alcohol and Drug Authority, 1977, p. 5)

Elsewhere in Australia at this time the treatment of problematic users of alcohol outside MHS operated facilities in separate specialist treatment services were also established (National Health and Medical Research Council, 1975; Santamaria, 1972).

This shift away from the MHS was sustained by a revised understanding that alcoholism was not of itself a mental illness, even though there may have be specific alcohol-caused mental disorders (Kiloh \& S, 1971; Kissin \& Begleiter, 1977) The specialist treatment system sought to better manage those who had previously cycled in and out of mental hospitals and prisons, in a revolving door-like system which existed in WA as well as a number of other jurisdictions (Fagan \& Mauss, 1978-1979; Gallant et al., 1973; Saeta \& Smiland, 1970).

However, these reforms did not apparently improve the management of long-term chronic problematic users, as there was an expectation the ADA would develop services to engage early stage problematic users of alcohol (Ellis, 1971, 1984).

The ADA reforms coincided with the election of the Whitlam Federal Labor Government in December 1972, which enabled WA and the other States, through the Community Health Program established by the Hospitals and Health Services Commission Act 1973 (a Commonwealth piece of legislation), to construct a separate specialist treatment system for alcohol and other drug users, as well as community mental health facilities.

Throughout the 1970s and early 1980s the ADA actively expanded and established a comprehensive range of client services, in the form of acute detoxification, medium and long-term residential programs, outpatient clinics and Community Teams.

An innovative development was establishing a network of Community Teams in the Perth metropolitan area and major regional centres, which had a broad ambit to deliver 'counselling, training, consultancy and community liaison', encompassing both Indigenous and non-Indigenous client groups (Western Australian Alcohol and Drug Authority, 1997, p. 15).

However, by the mid 1980s inpatient programs at both Quo Vadis and Ord Street Hospitals were closed. (Smith, 1981). The Byford Inebriates Centre (BIC), which the Department of Corrections had opened in late 1971 and operated a prison farm to manage convicted inebriates separate from Karnet Prison, was transferred to the ADA in 1974, which had renamed it Quo Vadis Hospital.

Quo Vadis Hospital operated as a destination for a similar population of men to those previously managed at the BIC. Its mission was described as being as a medium term residential program with 'therapeutic procedures ... of less intensity to those which exist at the Ord Street Hospital ... geared towards the long-term resocialisation of the patient through group techniques and work orientated activities' (Western Australian Alcohol and Drug Authority, 1975, p. 5).

The closure of Quo Vadis Hospital was a recognition that services

'could be provided more efficiently by a nongovernment agency ... (and accordingly the ADA had) negotiated with a number of agencies to this end. Successful negotiations have been concluded with the Salvation Army, which has an Alcohol Rehabilitation Centre at Seaforth (Gosnells).' (Western Australian Alcohol and Drug Authority, 1984, p. 5) 


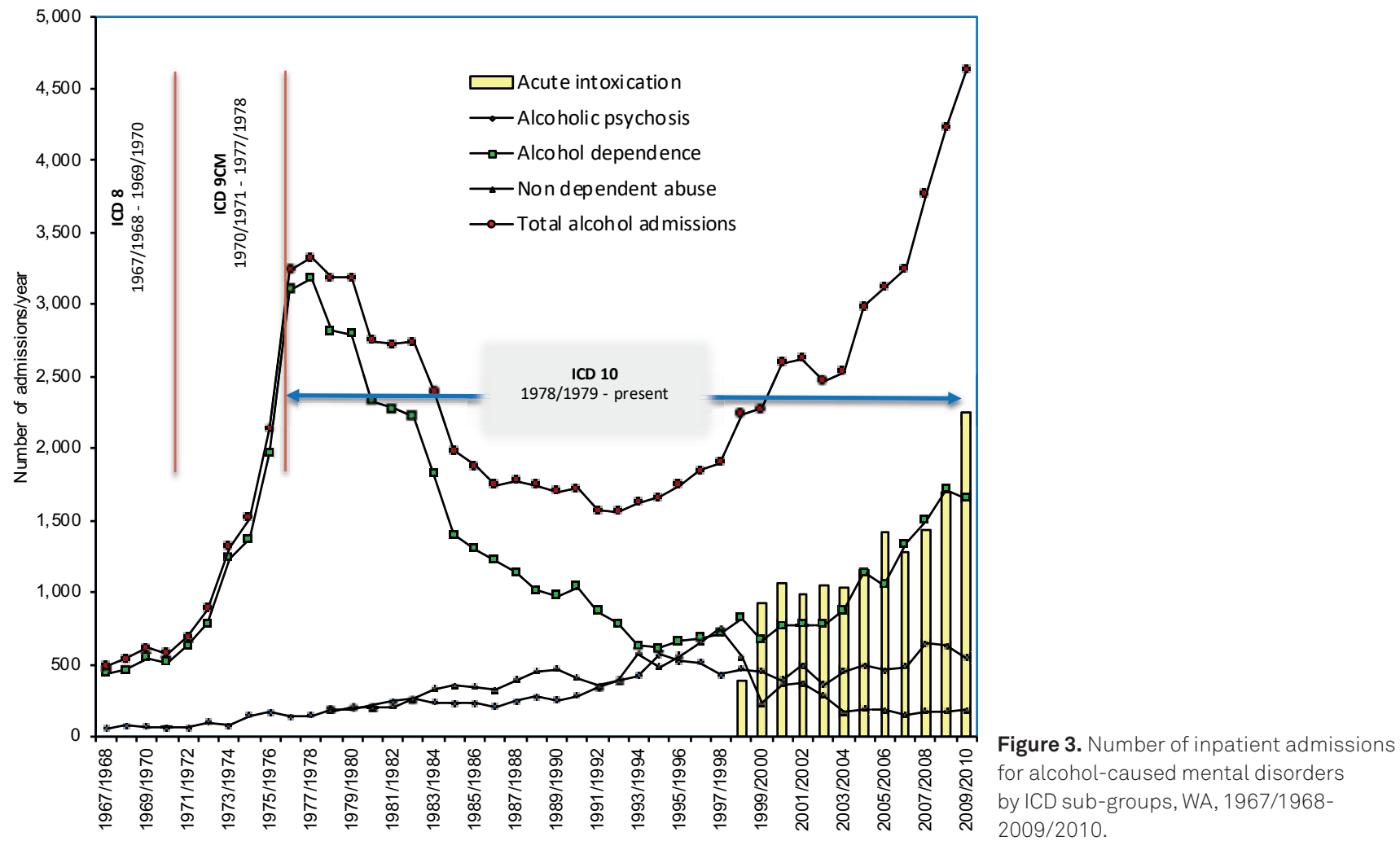

The Salvation Army Bridge Program continues to this day with a three-staged process of detoxification at Bridge House, a 13-week residential program at the Harry Hunter Recovery Centre and a post-discharge counselling and continuing care service.

Figure 3 refers to the period from 1967/1968 to 2009/2010 and involves counts of all alcohol-caused disorders extracted from the HMDS which recorded a principal diagnosis plus one or more secondary (underlying) diagnoses for all hospital discharges.

Data in Figure 3 indicates changes in coding protocols may create unusual trends, such as the condition Acute intoxication (F10.0), first evident in data for the year 1998/1999. The pattern with Alcohol dependence (303 in ICD 9CM and F10.2 in ICD 10) shows a marked decline from an annual peak of more 2,700 admissions in $1976 / 1977$ and $1977 / 1978$, to nearly 450 in $1994 / 1995$, with some growth since then to about 1,700 admissions per year.

Whilst annual counts of Acute intoxication and Alcohol dependence have increased since the mid 1990s, counts for admissions involving Non-dependent abuse (305.0 -
305.3 and F10.1) and Alcoholic psychosis (291 and F10.3 F10.) have remained relatively constant.

There is also a separate national data system, the Alcohol and Other Drug Treatment Services National Minimum Data Set (AODTS NMDS), related to annual admissions to funded alcohol and other drug treatment services, encompassing both residential and non-residential services, from 2001/2002. ${ }^{7}$

Data for WA from the AODTS NMDS is only available from the year 2007/2008. Prior to the AODTS NMDS data, only ADA treatment utilisation data exists for the period $1974 / 1975$ to $2006 / 2007$.

These two sources of data shows that until the early 1980s, alcohol-related cases constituted about three quarters of all ADA treatment episodes. Following the closure of the two ADA hospitals in the mid 1980s, the proportion of alcohol-related cases decreased to about one quarter of all episodes by the year 2000 .

Since both ADA and NGO data has been available from the AODTS NMDS, in WA alcohol-related episodes have increased from about one third of all episodes in $2006 / 2007$, to nearly half by the end of the period.

\footnotetext{
7 Overseen by the Australian Institute of Health and Welfare: https://www.aihw.gov.au/about-our-data/our-data-collections/alcohol-other-drugtreatment-services
} 


\section{Third era}

This era refers to the period from the late 1990s to 2015, when the ADA assumed a residual treatment role, in that it only operated Next Step, an inpatient short-term detoxification facility, plus a limited outpatient service. ${ }^{8}$

This reform was outlined in the WA Strategy Against Drug Abuse Action Plan 1997-1998, the genesis of which stemmed from the election in 1993 of the Court Liberal government, described as 'the most significant change to the alcohol and drug field in this State since of the inception of the Authority in 1974' (Western Australian Alcohol and Drug Authority, 1998, p. 5).

In this era NGO-based services became the primary model of delivery of services, which developed in November 1997 after the ADA's Community Teams were replaced by Community Drug Service Teams (CDSTs).

This model arose from government's embrace of principles of economic rationalism, based on efficiency and contracting out of services. One consequence of this reform was that direct service provision by government was limited to high cost programs, such as inpatient detoxification. ${ }^{9}$

In early 2003 DAO implemented an expanded model of funding area-based co-located treatment services, Community Alcohol and Drug Services (CADS), a feature was that the financial responsibility for establishing and running each service was underwritten by DAO ${ }^{10}$

This involved co-location of NGO service providers and DAO-employed medical and other professional health providers in CADS, as 'a one-stop shop for clients in that both Next Step and a range of non-government and other providers including GPs are located together, providing a wide range of services, support and referral' (Drug and Alcohol Office, 2003, p. 4).

The first such service was in the south metropolitan region catchment area, with three more CADS established in the rest of the metropolitan area by the end of 2007. ${ }^{11}$ The final configuration of this arrangement is four metropoli$\tan$ CADS, seven regional CADS, the Next Step service and a Drug and the Alcohol Youth Service in East Perth, adjoining Next Step. ${ }^{12}$

\section{Post 2015: MHS model of management of services}

There has been a recent reform, with the reabsorption in July 2015 of the ADA into the Mental Health Commission.

The 2015 reforms deserve close scrutiny as they in some respects repudiate a key principle that had underpinned service provision over the 40 year period since the mid 1970s. This was that all treatment should be undertaken voluntarily, embodied in the development of specialist alcohol and other drug treatment service providers and the limited involvement of the MHS in delivery of services. ${ }^{13}$

This reform means that alcohol and other drug treatment services are again located within a much larger department structure of the Mental Health Commission, which shares some similarities to the first era, when the management of those affected by alcohol and other drugs was also located within the mental health rather than public health system.

Although most services are now largely delivered by NGOs, except for a medically managed inpatient detoxification unit, this raises concerns about the loss of the independence that was contained in the ADA enabling legislation.

Policy makers are also actively considering a proposal to re-establish a program of civil commitment in WA, that will target problematic users of amphetamines, as well as alcohol and other substances, which will create a system of coercive 'treatment' based on abstinence oriented programs. (Brookes, 1 November 2019)

The erosion of voluntarism is claimed as necessary by government so it can compel problematic users of alcohol, as well as other drugs, to participate in treatment through interventions and intervention orders overseen by the courts (Corrective Services Minister, 6 August 2018).

There seems to be a lack of historical understanding of the poor outcomes of problematic users of alcohol who were subject to compulsion in the first era in WA between 1900 and 1975. This is because in a 9 March 2018 media statement the Minister for Corrective Services asserted a proposed treatment unit in Casuarina Prison would the

8 Aston Hospital had been renamed the Central Drug Unit, which was subsequently renamed 'Next Step Specialist Drug and Alcohol Services' in April 1999, as a registered business name, under the Business Names Act 1962.

9 However, this model of contracting out was modified with respect to the two CDSTs established in the northern half of the State, as the contracts were awarded to the two already existing publicly operated regional health services.

10 The ADA was included under a new administrative arrangement within the Drug and Alcohol Office, established in July 2002, which aggregated the Mental Health and Public Health Divisions of the Department of Health, together with the WA Drug Alcohol Strategy Office and Next Step. (Health Department of Western Australia, 2002, p. 46)

11 Annual report, Drug and Alcohol Office, 2006/2007,7.

12 https://www.mhc.wa.gov.au/getting-help/community-alcohol-and-drug-services/

13 The Mental Health Commission was established in March 2010, created by the transfer of the Mental Health Division of the Health Department of WA. 
'first of its kind in Australia' (Minister for Corrective Services, 9 March 2018).

\section{Discussion}

Policies in WA were informed by legislative approaches elsewhere and also shaped by broader social movements with impacted on treatment approaches, such as the deinstitutionalisation movement, articulated by the anti-psychiatry movement (Cunningham Dax, 1992).

The adoption of civil commitment in WA suggests that governments may seek to adopt such coercive measures to demonstrate they are 'doing something' about problems related to the use of alcohol and other drugs (New Zealand Law Reform Commission, 2011; Shea, 2005; Swan \& Alberti, 2004; Webb, 2003).

Recent examples include the Northern Territory's Alcohol Mandatory Treatment Act 2013, ${ }^{14}$ in New South Wales the Drug and Alcohol Treatment Act 2007, in Victoria the Severe Substance Dependence Treatment Act 2010 and in New Zealand the Substance Addiction (Compulsory Assessment and Treatment) Act 2017 (Caldwell, May 2016; Davidson, 14 November 2014, 18 August 2017; Edraki \& Carrick, 4 April 2019; Everingham, 21 April 2017; Lander, Gray, \& Wilkes, 2015; McSherry, 2011; Pricewaterhouse Coopers Indigenous Consulting, 2017).

However, in spite of the deinstitutionalisation of psychiatric treatment, there has been an expansion of medicalisation of the social problems in new areas, underscoring how changes in social attitudes and cultural values affect how about consumption of alcohol and intoxication is understood (Fox \& MacAvoy, 2011).

Another example has been a shift in attitudes about excess consumption of alcohol and over-eating of other foods, which has 'transformed practices embedded in social or cultural relations into explicit medical practices' (Mayes, 2014). There has an embrace of policies that rely on selfregulation, what has been referred to as biopolitical utilisation of lifestyle to shape choice, a neo-liberal concept, which in relation to alcohol, would argue that government should step back and let the market operate (Mayes, 2016).

The increasing focus by government on population level research and mass media public health advertising, such as Drinksafe and Alcohol Think Again ${ }^{15}$ campaigns in the third era in WA, are examples of this approach (Clarkson et al., 1998; Health Department of Western Australia, 1988; Xiao, Rowe, Somerford, Draper, \& Martin, 2008).
This emphasis on self-regulation results in government being concerned with establishing an architecture of governance, whereby it acts to shape 'the welfare of the population, the improvement of its condition ... longevity, health, etc.' (Foucault, 1991).

However, this freedom may not extend to those who are problematic users of alcohol, for whom treatment may be justified due to a perceived inability to self-regulate, in spite of the existence of adverse social and other circumstances.

'Alcohol is a drug, and its direct, relatively predictable, and uniform actions on the human organism have been well documented.

Yet alcohol problems are experienced by specific individuals, who live and move and have their being within very different social, psychological, and cultural environments. (Institute of Medicine, 1990, p. 20)

An impetus for inebriate legislation as a form of social control may have also been driven by social factors, as this legislation had a disproportionate impact on working Australians who were problematic users of alcohol, perpetuating a gendered and class perspective on understanding alcohol problems.

'By the First World War the efforts of reformers had resulted in longer periods of prison and mental hospital incarceration for those working-class inebriates deemed to be suffering the disease of habitual drunkenness.' (Garton, 1987, p. 53)

Furthermore, as well as this class bias in relation to those committed, it is also likely that in WA, as has been noted in the UK at this time, '(t)he power to commit offenders to inebriate reformatories was heavily implemented in cases of neglect and child cruelty' (Berridge, 2004, p. 4).

Changes in social attitudes may have also contributed to reduced support and justification for the use of inebriate legislation in relation to women, marriage and family breakdown, parenting and control over disadvantaged families (Hetherington, 2013, 1988). However social controls over men who were problematic users of alcohol did not so quickly fall out of favour, as the civil commitment regime established by the CIRA continued until the early 1970s.

In addition to legal social controls which targeted problematic users through by civil commitment, there are also 
formal and informal social controls, which constitute a form of 'social pressure' on problematic users of alcohol and other drugs to enter treatment programs (Wild, 2006).

It is noted that addition to mental health and police legislation, there were other forms of control to counter the perceived threat of alcohol to social order, such as provisions in matrimonial laws, where alcoholism was a ground for divorce under the State's Matrimonial Causes and Personal Status Code $1948 .^{16}$

'In the case of a husband defendant, habitual drunkenness for four years or more and during that period habitually leaving the plaintiff without means of support or being guilty of habitual cruelty towards her; and in the case of a wife defendant, habitual drunkenness for four years or more and during that period habitually neglecting her domestic duties or rendering herself unfit to discharge them.' Section $15(\mathrm{~g})$

There was some reluctance to no longer support civil commitment in WA, even though the Mental Health Act 1962 was a key reform in WA and policy makers were aware for some time of the limitations of institutional-based treatment of mental disorders, including problematic users of alcohol (Brunton, 2003; Cunningham Dax, 1989; Harcourt, 2011; Shea, 2005).

This 1962 reform was presaged by a wide-ranging survey of mental health services in Australia in the mid 1950s, which had alerted policy makers to concerns about limitations of a MHS-centric approach (Stoller \& Arscott, 1955).

It was not possible within the bounds of this study to determine the relationship between the state population's demographic structure and alcohol problems, which had become skewed by the influx of miners after the discovery of gold in the Coolgardie in 1890s.

The impetus for economic development in WA created a tension between development and economic policies that promoted development based on mining and extractive industries and attendant social problems related to alcohol use, and the need for investment in services to assist problematic users (Bolton \& Joske, 1982; Ellis, 1984).

The high levels of problematic use of alcohol that had existed in WA from its colonial past and which continued at least until the outbreak of World War I, meant that the MHS was encumbered with a significant burden in manag- ing large numbers of individuals demonstrating both acute and chronic effects of alcohol use.

There has been a similar impact on the criminal justice system in managing problematic users of alcohol on the basis of public order consequences of alcohol, related to public drunkenness. This resulted in recidivist offenders cycling through the courts and prison system in WA until public drunkenness was decriminalised in 1990 (Swensen, 2017).

The policy response in the first era relied heavily on coercive approaches by the MHS operated in conjunction with the criminal justice system, as a framework that relied on punitive controls as the 'price' for the system of controls on alcohol (Babor et al., 2010; Edwards et al., 1997).

This system of social controls meant that until the reforms of the mid 1970s, when for the first time there was a significant investment in the development of specific purpose treatment system to treat alcohol and drug users, in WA there had been few choices beyond the spectre of cycles of imprisonment for repeated public drunkenness or committal in mental health facilities.

A final comment, in the nature of a footnote, should be made about the management of problematic use of alcohol by Indigenous people. Indigenous people are barely present in official reports and statistical summaries reviewed because they were not managed in mainstream services in the three eras outlined.

Furthermore, Indigenous people continue to be largely managed on a different basis to other problematic users of alcohol in WA through a system of separate treatment. One of the key services is the operation of sobering up centres, which were established as an alternative to police lockups as a place for short term protective care of alcohol intoxicated people (Swensen, 2008).

This approach was specifically designed to not be a treatment service, even though it is likely many of those taken to a SUC had serious alcohol dependency related issues (Hunter, Hall, \& Spargo, 1991; Hunter \& Harvey, 2002).

\section{References}

Babor, T.F., Caetano, R., Casswell, S. Edwards, G., Giesbrecht, N., Graham, K. et al. (2010). Alcohol no ordinary commodity: research and public policy. New York: Oxford University Press.

16 This WA legislation was repealed by the Commonwealth Matrimonial Causes Act 1959 (MCA), which came into effect 1 February 1961 and established Australia's first national law on marriage and divorce. The MCA included the ground for dissolution of a spouse being a 'habitual drunkard' for not less than two years. Section 28 (f). This ground ceased to exist when the Family Act 1975 came into effect on 1 January 1976. 
Berridge, V. (2004). Punishment or treatment? Inebriety, drink and drugs, 1860-2004. Lancet, 364, Suppl 1, s4-s5.

Bolton, G.C. \& Joske, P. (1982). History of Royal Perth Hospital. Perth, WA: University of Western Australia Press.

Brookes, S. (1 November 2019). System 'failing' meth addicts with psychosis. Midland Reporter. Retrieved from https://www.communitynews.com.au/midland-reporter/news/system-failingmeth-addicts-with-psychosis/

Brunton, W. (2003). The origins of deinstitutionalisation in New Zealand. Health and History, 5(2), 75-103. Retrieved from http:// www.historycooperative.org/journals/hah/5.2/brunton.pdf

Burchell, G., Gordon, C. \& Miller, P. (Eds.). (1991). The Foucault effect: Studies in governmentality with two lectures by and an interview with Michel Foucault. London, UK: Harvester Wheatsheaf.

Caldwell, V. (May 2016). Guest editorial: Substance Addiction Bill briefing. Matters of Substance. Retrieved from https://www. drugfoundation.org.nz/matters-of-substance/may-2016/ substance-addiction-bill-briefing/

Carr, E.H. (1961). What is history. Second edition (reprinted 1990). Melbourne, VIC: Penguin.

Clarkson, J., Corti, B., Donovan, R., Pikora, T., Jalleh, G. \& Wood L. (1998). Play hard drink safe project evaluation report. Perth, WA: Health Promotion Evaluation Unit, Department of Public Health \& Graduate School of Management, University of Western Australia.

Corrective Services Minister. (6 August 2018). Western Australia's first female drug treament prison opens. Retrieved from https://www.mediastatements.wa.gov.au/Pages/McGowan/2018/08/Western-Australias-first-female-drug-treatment-prison-opens.aspx

Cunningham Dax, E. (1989). The first 200 years of Australian psychiatry. Australian and New Zealand Journal of Psychiatry, 23, 103-110.

Cunningham Dax, E. (1992). The evolution of community psychiatry. Australian and New Zealand Journal of Psychiatry, 26, 295-301.

Davidson, H. (14 November 2014). NT woman dies at unit for mandatory alcoholism treatment. Retrieved from http://www.theguardian.com/australia-news/2014/nov/14/nt-woman-dies-at-unitfor-mandatory-alcoholism-treatment

Davidson, H. (18 August 2017). Northern Territory repeals alcohol laws 'discriminatory' to Indigenous people. Retrieved from https://www.theguardian.com/australia-news/2017/aug/18/ northern-territory-repeals-alcohol-laws-discriminatory-to-indigenous-people

Department of Treasury and Finance. (2004). An economic history of Western Australia since colonial settlement. Research paper: 175th anniversary of colonial settlement 1829-2004. Perth, WA: Department of Treasury and Finance.

Dingle, A. E. (1980). The truly magnificent thirst: An historical survey of Australian drinking habits. Historical Studies, 19, 227-249.

Drug and Alcohol Office. (2003). Annual report, 2002/2003. Perth, WA: WA and Alcohol and Drug Authority.

Edraki, F. \& Carrick, D. (4 April 2019). Should drug-addicted kids be forced into rehab? An abuse survivor and a magistrate think so. Retrieved from https://www.abc.net.au/news/2019-04-05/ mandatory-rehab-for-kids-who-are-addicted-to-drugs-andalcohol/10963436

Edwards, G., Anderson, P., Babor, T.F., Casswell, S., Ferrence, R., Giesbrecht, N. et al. (1997). Alcohol policy and the public good. NY: Oxford University Press.

Ellis, A.S. (1971). Investigation into drugs and alcohol: Final report. Perth, WA: Health Department of Western Australia
Ellis, A.S. (1984). Eloquent testimony: The story of the mental health services in Western Australia 1830-1975. Perth, WA: University of Western Australia Press.

Everingham, S. (21 April 2017). NT government's forced alcohol rehab program found to be expensive, with no long-term health impacts. $A B C$ News. Retrieved from https://www.abc.net.au/ news/2017-04-21/nt-mandatory-alcohol-rehab-has-littlehealth-impact-report-finds/8459998

Fagan, R.W. \& Mauss, A. L. (1978-1979). Padding the revolving door: an initial assessment of the Uniform Alcoholism and Intoxication Treatment Act in practice. Social Problems, 26, 232-246.

Foucault, M. (1991). Governmentality. In G. Burchell, C. Gordon, \& P. Miller (Eds.), The Foucault effect: Studies in governmentality with two lectures by and an interview with Michel Foucault. London, UK: Harvester Wheatsheaf.

Fox, A. \& MacAvoy, M. (Eds.). (2011). Expressions of drunkenness (four hundred rabbits). NY: Routledge.

Gallant, D.M., Bishop, M.P., Mouledoux, A., Faulkner, M.A., Brisolara, A. \& Swanson, W. A. (1973). The revolving door alcoholic: An impasse in the treatment of the chronic alcoholic. Archives of General Psychiatry, 28, 633-635.

Garton, S. (1987). Once a drunkard always a drunkard: Social reform and the problem of 'habitual drunkenness' in Australia, 1880-1914. Labour History, 53, 38-53.

Harcourt, B.E. (2011). Reducing mass incarceration: lessons from the deinstitutionalisation of mental hospitals in the 1960s. Ohio State Journal of Criminal Law, 9(1), 53-88.

Health Department of Western Australia. (1988). Drinksafe. Alcohol and health in Western Australia - a resource book. Perth, WA: Health Department of Western Australia.

Health Department of Western Australia. (2002). Annual report 2001/2002: Department of Health, Royal Street. Perth, WA: Health Department of Western Australia.

Hetherington, P. (2013). The marriage knot: Marriage and divorce in colonial Western Australia 1829-1900. Perth, WA: UWA Publishing.

Hetherington, P. (Ed.). (1988). Childhood and society in Western Australia. Perth, WA: University of Western Australia Press.

Hunter, E., Hall, W., \& Spargo, R. (1991). Alcohol consumption and its correlates in a remote Aboriginal community. Aboriginal Law Bulletin, 38-. Retrieved from www.austlii.edu.au/au/journals/ AboriginalLB/1991/38.html

Hunter, E. \& Harvey, D. (2002). Indigenous suicide in Australia, New Zealand, Canada and the United States. Emergency Medicine, 14,14-23.

Inebriates Advisory Board. (August 1969). A review of six years activity. Perth, WA: Inebriates Advisory Board, Chief Secretary's Department.

Inspector General of the Insane. (1918). Annual report 1917-1918. Perth, WA: Western Australian Parliament.

Inspector General of the Insane. (1926). Annual report 1925-1926. Perth, WA: Western Australian Parliament.

Inspector General of the Insane. (1928). Annual report 1927-1928. Perth, WA: Western Australian Parliament.

Institute of Medicine. (1990). Broadening the base of treatment for alcohol problems. Washington, DC: National Academy Press.

Kiloh, L.G. \& S, B.D. (Eds.). (1971). 29th International Congress on Alcoholism and Drug Dependene, Sydney, February 1970. Melbourne, VIC: Butterworths.

Kirkby, D. (2003). 'Beer, glorious beer': gender politics and Australian popular culture. Journal of Popular Culture, 37(2), 244-256.

Kirkby, D. (2006). Drinking the good life: Australia c 1880-1980. In Holt MP (Ed.), Alcohol: A social and cultural history. Oxford: Berg. 
Kirkby, D., Luckins, T. \& McConville, C. (2010). The Australian pub. Sydney, NSW: University of New South Wales Press.

Kissin, B. \& Begleiter, H. (Eds.). (1977). The biology of alcoholism. Volume 5: Treatment and rehabilitation of the chronic alcoholic NY: Plenum Press.

Kritzman, L.D. (Ed.) (1988). Michel Foucault: Politics, philosophy, culture. Interviews and other writings 1977-1984. London, UK: Routledge.

Lander, F., Gray, D. \& Wilkes, E. (2015). The Alcohol Mandatory Treatment Act: evidence, ethics and the law. Medical Journal of Australia, 203(1), 47-49.

Mayes, C. (2014). Medicalisation of eating and feeding. Retrieved from https://www.academia.edu/12323991/Medicalization_of_ Eating_and_Feeding

Mayes, C. (2016). The biopolitics of lifestyle: Foucault, ethics and healthy choices Abingdon, Oxfordshire, UK: Rouytledge.

McGregor, J. E. (2012). Drink and the city: Alcohol and alcohol problems in urban UK since the 1950s. Nottingham, UK: Nottingham University Press.

McSherry, B.M. (2011). Laws to detain individuals with substance dependency: Breaching human rights or restoring health? Journal of Law and Medicine, 19, 225-231. Retrieved from https:// ssrn.com/abstract $=2490970$

Measham, F. (2004). Play space: historical and socio cultural reflections on drugs, licensed lesiure locations, commercialisation and control. International Journal of Drug Policy, 15, 337-345.

Measham, F. \& Brain, K. (2005). Binge drinking, British alcohol policy and the new culture of intoxication. Crime Media Culture, 1(3), 262-283.

Medical Journal of Australia. (1925). The mental hospital service. Medical Journal of Australia, 678-680.

Medical Journal of Australia. (1926). The mental hospital services. Medical Journal of Australia, 2, 705-708.

Medical Journal of Australia. (1927). Mental hospital services. Medical Journal of Australia, 755-758.

Mental Health Services (1969). Annual report of the Mental Health Services for 1967/1968. Perth, WA: Mental Health Services.

Minister for Corrective Services. (9 March 2018). First of its kind alcohol and other drug treatment prison announced (media statement). Retrieved from https://www.mediastatements.wa. gov.au/Pages/McGowan/2018/03/First-of-its-kind-alcoholand-other-drug-treatment-prison-announced.aspx

Moriyama, I. M., Loy, R.M., Robb-Smith, A.H.T., Rosenberg, H.M. \& Hoyert, D. L. (2011). History of the statistical classification of diseases and causes of death. Retrieved from Washington, DC: https://www.cdc.gov/nchs/data/misc/classification_diseases2011.pdf

National Health and Medical Research Council. (1975). Report of the Standing Committee on the Health Problems of Alcohol. Canberra, ACT: Australian Department of Health.

New Zealand Law Reform Commission. (2011). Controlling and regulating drugs: A review of the Misuse of Drugs Act 1975. Wellington, NZ: Law Commission.

Pearl, C. (1969). Beer, glorious beer. Melbourne, VIC: Thomas Nelson.

Petersen, A. \& Lupton, D. (1996). The new public health: health and self in the age of risk. London: Sage.

Phillips, W. (1980). Six o'clock swill: the introduction of early closing of hotel bars in Australia. Historical Studies, 19, 250-266.

Pricewaterhouse Coopers Indigenous Consulting. (2017). Evaluation of the Alcohol Mandatory Treatment Program. Retrieved from https://digitallibrary.health.nt.gov.au/prodjspui/bitstream /10137/1226/1/Alcohol\%20Mandatory\%20Treatment\%20 Evaluation\%20Report.pdf
Rosen, A. (2006). The Australian experience of deinstitutionalisation: interaction of Australian culture with the development and reform of its mental health services. Acta Psychiatrica Scandinavica, 113, 81-89.

Royal Commission In Lunacy. (1922). Report and appendices (Angwin chairman). Retrieved from http://www.parliament.wa.gov. au/intranet/libpages.nsf/WebFiles/Royal+Commissions+-+Re port+and+appendices+of+the+royal+commission+in+lunacy /\$FILE/Report+and+appendices+of+the+royal+commission+ in+lunacy.pdf

Saeta, P.M. \& Smiland, W.M. (1970). Public inebriate health: the legislature and the revolving door. Pacific Law Journal, 1, 65-96.

Santamaria, J.N. (1972). The social implications of alcoholism. Medical Journal of Australia, 2, 523-528.

Sargent, M. (1979). Drinking and alcoholism in Australia: a power relations theory. Melbourne, VIC: Longman Cheshire.

Shea, P. (2005). The New South Wales Inebriates Act: going, going, gone? Australasian Psychiatry, 13, 195-197.

Smith, D.i. (1981). Evaluation of the Quo Vadis Hospital rehabilitation program. Paper presented at the Proceedings of 1981 Autumn School of Studies on Alcohol and Drugs, Melbourne, VIC.

Stannage, C.T. (Ed.) (1981). A new history of Western Australia. Perth, WA: University of Western Australia Press.

Statistics Branch. (1971). Hospital morbidity statistics: short stay hospitals 1971. Perth, WA: Statistics Branch, Public Health Department.

Stoller, A. \& Arscott, K.W. (1955). Report on mental health facilities and needs of Australia. Retrieved from Canberra, ACT:

Straw, L.S.L. (2013). Drunks, pests and harlots: criminal women in Perth and Fremantle, 1900-1939. Kilkerran, Scotland: Humming Earth.

Swan, A. \& Alberti, S. (2004). The Alcoholics and Drug Dependent Persons Act (ADDPA) 1968: a review. Melbourne, VIC: Turning Point Alcohol and Drug Centre.

Swensen, G. (2008). Utilisation of sobering up centres, 1990-2007. Retrieved from Perth, WA:

Swensen, G. (2016). Public space and alcohol advertising: exploratory role of local government. International Journal of Alcohol and Drug Research, 5(3), 117-123.

Swensen, G. (2017). The management of public drunkenness in Western Australia: policing the unpoliceable? Limina: A Journal of Historical and Cultural Studies, 23(1), 1-24.

Swensen, G. \& Unwin, E. (1995). Indicators of drug use in Western Australia, 1982-1992. Perth, WA: Epidemiology Branch, State Health Purchasing Authority, Health Department of Western Australia.

Webb, M.B. (2003). Compulsory alcoholism treatment in New South Wales. Medicine and Law, 22, 311-327.

Western Australian Alcohol and Drug Authority. (1977). Annual report 1976-1977. Perth, WA: Western Australian Alcohol and Drug Authority.

Western Australian Alcohol and Drug Authority. (1975). Annual report 1974-1975 (draft unpublished). Perth, WA: Western Australian Alcohol and Drug Authority.

Western Australian Alcohol and Drug Authority. (1984). Annual report 1983-1984. Perth, WA: Western Australian Alcohol and Drug Authority.

Western Australian Alcohol and Drug Authority. (1997). Annual report 1996-1997. Perth, WA: Western Australian Alcohol and Drug Authority.

Western Australian Alcohol and Drug Authority. (1998). Annual report 1997-1998. Perth, WA: Western Australian Alcohol and Drug Authority. 
Wild T C. (2006). Social control and coercion in addiction treatment: towards evidence-based policy and practice. Addiction, 101, 40-49.

Xiao, J., Rowe, T., Somerford, P., Draper, G. \& Martin, J. (2008). Impact of alcohol on the population of Western Australia. Perth, WA: Epidemiology Branch, Department of Health WA.

\section{History}

Received: November 14, 2019

Accepted: April 1, 2020

\section{Declaration of competing interests}

None

\section{ORCID}

Greg Swensen

(10) https://orcid.org/0000-0001-7790-230X

\section{Greg Swensen}

Law School

University of Western Australia

35 Stirling Highway

Crawley, Western Australia 6009

Australia

swengreg@gmail.com 